\title{
Prevalence of depressive symptoms and associated factors among patients with tuberculosis attending public health institutions in Gede'o zone, South Ethiopia
}

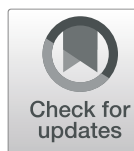

\author{
Kalkidan Yohannes ${ }^{1 *}$ D, Hirbaye Mokona', Lulu Abebe ${ }^{1}$, Mohammed Feyisso², Adane Tesfaye², \\ Getachew Tesfaw ${ }^{3}$ and Getinet Ayano ${ }^{4,5}$
}

\begin{abstract}
Background: Depression is a common mental disorder among patients with tuberculosis and it is associated with a greater risk of suicide, multidrug-resistant tuberculosis, and poor quality of life. Evidence suggests the early identification of depression among patients with tuberculosis is important to decrease adverse outcomes. However, there are limited studies that examined the prevalence and determinants of depressive symptoms among patients with tuberculosis. This study aimed to assess the prevalence and associated factors of depressive symptoms among patients with tuberculosis attending public health institutions in Gede'o zone, South Ethiopia.

Methods: An institution-based a cross-sectional study was conducted from November 1 to December 30, 2018, among a randomly selected sample of 415 patients with tuberculosis attending public health institutions in Gede'o zone, South Ethiopia. Patient Health Questionnaire (PHQ-9) was used to assess depressive symptoms. Logistic regression was used to identify the potential risk factors of depressive symptoms. The strength of the association was presented by crude odds and adjusted odds ratio with their corresponding 95\% Cl. Finally, the statistical significance was set at $p<0.05$.

Results: The prevalence of depressive symptoms was found to be $45.5 \%(95 \% \mathrm{Cl} ; 41.1-50.1 \%)$ among patients with tuberculosis; $33.3 \%$ had moderate, $9.8 \%$ had moderately severe, and $2.4 \%$ had severe depression. After adjusting for the possible confounders, being on re-treatment for tuberculosis ( $A O R=2.47,95 \% \mathrm{Cl}: 1.17-5.22$ ), aged $\geq 45$ years ( $\mathrm{AOR}=2.41$, 95\% Cl: 1.09-5.32), having poor social support (AOR $=4.21,95 \%$ Cl: 2.10-8.47), and Tuberculosis/Human Immunodeficiency Virus (TB/HIV) co-infection) (AOR $=3.96,95 \% \mathrm{Cl} 2.0,7.84$ ) were significantly associated with depressive symptoms among patients with TB.

Conclusions: This study suggests that a substantial percentage of patients with TB had depressive symptoms (45.5\%). TB/ HIV coinfection, being on re-treatment for tuberculosis, those having poor social support, patients aged 45 and above were factors associated with depressive symptoms. Routine screening of depression among patients with TB is warranted. Moreover, patients with TB falling into the risk categories should be more carefully monitored for depression and when possible referred to mental health professionals.
\end{abstract}

Keywords: Depressive symptoms, Prevalence, Tuberculosis, Ethiopia

\footnotetext{
* Correspondence: kalkid29@yahoo.com

'Department of Psychiatry, College of Medicine and Health Sciences, Dilla University, P.O. Box 419, Dilla, Ethiopia

Full list of author information is available at the end of the article
}

(c) The Author(s). 2020 Open Access This article is licensed under a Creative Commons Attribution 4.0 International License, which permits use, sharing, adaptation, distribution and reproduction in any medium or format, as long as you give appropriate credit to the original author(s) and the source, provide a link to the Creative Commons licence, and indicate if changes were made. The images or other third party material in this article are included in the article's Creative Commons licence, unless indicated otherwise in a credit line to the material. If material is not included in the article's Creative Commons licence and your intended use is not permitted by statutory regulation or exceeds the permitted use, you will need to obtain permission directly from the copyright holder. To view a copy of this licence, visit http://creativecommons.org/licenses/by/4.0/. The Creative Commons Public Domain Dedication waiver (http://creativecommons.org/publicdomain/zero/1.0/) applies to the data made available in this article, unless otherwise stated in a credit line to the data. 


\section{Background}

Depression is a common and serious mental disorder, characterized by persistent sadness and a loss of interest in activities that you normally enjoy [1]. Aside from the emotional problems caused by depression, individuals can also present with a physical symptom [1-3]. It is also accompanied by an inability to carry out daily activities, for at least two weeks $[1,3]$. This disorder is a serious, recurrent one, which erodes the quality of life and fulfillment of social and familial roles [4], and the World Health Organization (WHO) ranks depression as the fourth leading cause of disability worldwide (8). It is the leading mental health-related cause of the Global Burden of Disease (GBD) [5]. According to the findings from the National Health Survey data, the prevalence of depressive episode in Ethiopia was 9.1\% [6]. Depression is a common comorbid condition of patients with TB [7] and it is associated with higher poor clinical outcomes [8].

TB is a widely spread infectious disease caused by the bacterium Mycobacterium tuberculosis. It typically affects the lungs (pulmonary TB), but can also affect other sites (extra-pulmonary TB) [9]. TB continues to remain a major health problem, especially in the developing world [10]. Despite the availability of effective chemotherapy, TB killed 1.3 million people in 2017. Globally, the best estimate is that 10 million people (range, 9-11.2 million) equivalent to 133 cases (range, 120-148) per 100,000 population developed TB disease in 2017: 5.8 million men, 3.2 million women and 1.0 million children [11]. According to the 2014 global report on TB published by the World Health Organization (WHO), Ethiopia has achieved all the three targets of the Millennium Development Goals (MDG) regarding TB prevention and controls [12].According to the report, the incidence rate of $\mathrm{TB}$ is falling significantly and the prevalence and the death rate due to TB have declined by more than $50 \%$ [12].

There is a dearth of data on the prevalence of depressive symptoms in TB patients in Ethiopia, however, a study conducted in Wolaita Sodo reported a 43.4\% prevalence of depression in TB patients [13]. A study conducted in the Jimma University Specialized Hospital and Jimma Health Center revealed 49\% of depression prevalence among TB patients [14]. Furthermore, another study in Butajira showed a high prevalence of probable depression, $54.0 \%$ among newly diagnosed TB patients [15].

Co-occurrence of TB and depression is associated with a range of adverse health outcomes, including functional impairment, increase medical costs, the emergence of multidrug-resistant $\mathrm{TB}$ and poor health-related quality of life [7, 16-19].Some evidence suggests that among TB patients, there were high prevalence rates of psychiatric comorbidity, especially depression, as well as specific psychological reactions and reviews indicating psychiatric complications as adverse effects of anti-TB medication [7, 20].

Multiple factors can affect depression among TB patients, including socio-demographic and economic factors: age of the patient, being female, marital status, income, occupation, perceived social support, perceived stigma to physical conditions, TB-HIV co-infection, hazardous alcohol use, and physical symptoms [13, 21-23].

Measurement of depression in TB patients is essential to have an in-depth understanding of the effect of disease on the mental health of the patient. In Ethiopia, there is limited literature regarding depression and important contributing factors like hazardous alcohol use, among TB patients. Therefore, this study aimed to assess the prevalence of depressive symptoms and associated factors among TB patients attending TB clinics of public healthcare institutions in Gede'o zone, South Ethiopia. The findings from this study will assist the national TB program to develop effective intervention strategies for TB patients with problems related to depression. Hence, the finding of this study will address a gap in formulating the necessary solutions.

\section{Methods \\ Study design and period}

An institution-based cross-sectional study was conducted from November 1 to December 30, 2018.

\section{Study site}

The study was conducted among adult patients attending a TB clinic in public health institutions of Yirgacheffe, Wonago and Dilla Zuriya districts, Gedeo zone, South Ethiopia. Gedeo zone is found in South Nations, Nationalities and Peoples' Regional States of Ethiopia, $359 \mathrm{~km}$ southeast of Addis Ababa (the capital city of Ethiopia). In the zone, there is one referral hospital, two primary hospitals, and 39 health centers. Except Dilla University Referral Hospital, none of them had mental health professional or no expert was participating in the Mental Health Gap Action Program (mh-GAP) training for primary care providers.

\section{Sample size determination and sampling procedure}

The sample size calculated using assumptions: margin of error 5, 95\% CI, the estimated prevalence of depression, 43.4\% from a study in Wolaita Sodo, Ethiopia [13] and the non-response rate of $10 \%$. The final calculated sample size was 415 . Study participants were proportionally allocated for each health facility, according to patient flow by referring to the previous year's annual reports. A systematic sampling technique was used to select study participants. Sampling interval was determined by dividing the total study population who had follow-up during 
the four-week data collection period by the total sample size, then the starting point was randomly selected.

\section{Study population}

All adult TB patients who were attending TB clinics of public health institutions in the Gede'o zone were studied populations. Patients aged 18 to 65 years old and patients who were on anti-TB medication for at least 2 weeks were included in the study. Patients who were severely ill during the study period were excluded.

\section{Data collection}

Data was collected by six clinical nurses who were assisted by two public health officers, working in the TB clinic of the respective study health institutions.

\section{Data collection instruments}

Interviewer-administered questionnaire was used to collect data, which contains data on socio-demographic characteristics of the participants, psychosocial characteristics, clinical characteristics, alcohol related characteristics, and data on the outcome variable (depressive symptoms).

\section{Perceived social support}

Data on social support was assessed by Oslo social support scale [24]. It is a three items social support scale (OSS-3. It covers different fields of social support by measuring the number of people the respondent feels close to, the interest and concern showed by others and the ease of obtaining practical help from others. It has the sum score scale ranging from 3 to 14 with three broad categories: "poor support" 3-8, "moderate support" 9-11 and "strong support" 12-14 [24].

\section{Perceived TB stigma scale}

Data on TB stigma felt by the patients was assessed by the TB stigma scale. It is 11-item scale that is used to assess the stigma felt by TB patients [25]. The instrument was adopted and translated to Amharic language and highly reliable in a pre-test (Cronbach's $\alpha=0.89$ ). Item scores of the stigma questions were summed to construct a single stigma variable. Participants were classified as having or not having perceived stigma using the mean of the stigma variable as a cut-off point $[25,26]$.

\section{Hazardous alcohol use}

Data on hazardous alcohol use was collected through the Alcohol Use Disorders Identification Test (AUDIT) [27]. It is a brief screening instrument designed for the early detection of hazardous and harmful alcohol use in a variety of settings. It focuses on both the past and current alcohol drinking. Each item is rated using itemspecific anchors scored 0 to 4 and summed for a total score of 0 to 40. A score of 8 or more is considered to indicate hazardous alcohol use. The AUDIT has been validated across genders and in a wide range of racial/ ethnic groups and is well-suited for use in primary care settings [27].

\section{Depressive symptoms}

Data on the outcome variable was collected through interviews using a standard questionnaire, Patient Health Questionnaire (PHQ-9) which is a 9-item depression screening and diagnostic questionnaire for major depressive disorder based on the Diagnostic Statistical ManualIV criteria with sensitivity $86 \%$ and specificity $67 \%$ [28]. The PHQ-9 appears to be a reliable and valid instrument and has been validated and used in Ethiopia. A score of 10 or more out of 27 indicates the presence of depressive symptoms. For severity classification, a score of 10 14 indicates 'moderate depression', 15-19 indicates 'moderately severe depression' and 20-27 indicates 'severe depression' [28].

\section{Data processing and analysis}

Data were cleaned, coded and entered to EPINFO version 7 and analyzed using SPSS-20 respectively. Using descriptive methods, the data were summarized and the estimated prevalence of depressive symptoms was determined. Associations of depressive symptoms and its factors were identified using logistic regression analyses. Following each bivariate regression, multivariable logistic regression models were constructed. The statistical significance was set at $p<0.05$.

\section{Results \\ Socio-demographic and economic characteristics of the participants}

A total of 409 participants took part in the present study (response rate $98.6 \%$ ) and the majority of the participants $(61.6 \%)$ were men. The mean age of the participant was 31.9 years $(\mathrm{SD}=11.85)$ and $53.1 \%$ were married. More than one-third (40.3\%) of the participants had attended primary school, (53.1\%) lives in rural areas, and the vast majority of the participants (78.2\%) earn less than 1539 ETB (54.19 USD) per month (Table 1).

Clinical characteristics of the participants (patients with TB) Of the 409 participants, 302 (73.8\%) were pulmonary TB patients, $250(61.6 \%)$ were in the intensive phase of the treatment, and $15.2 \%$ were re-treatment cases. One in five participants (20\%) were hazardous alcohol users, 71 (17.4\%) had comorbid HIV, and 22 (5.4\%) had comorbid chronic conditions. In two hundred thirty-six (57.7\%) of the TB patients, the illness had a duration of 6-12 months (Table 2). 
Table 1 Distribution of tuberculosis patients attending tuberculosis unit of public health institutions, Gede'o zone, South Ethiopia, $2018(n=409)$

\begin{tabular}{|c|c|c|c|}
\hline Variables & Categories & Frequency & Percent (\%) \\
\hline \multirow[t]{2}{*}{ Sex } & Male & 252 & 61.6 \\
\hline & Female & 157 & 38.4 \\
\hline \multirow[t]{4}{*}{ Age in years } & $18-29$ & 216 & 52.8 \\
\hline & $30-39$ & 98 & 24.0 \\
\hline & $40-49$ & 56 & 13.7 \\
\hline & 50 and above & 39 & 9.5 \\
\hline \multirow[t]{4}{*}{ Marital status } & Married & 217 & 53.1 \\
\hline & Single & 157 & 38.4 \\
\hline & Divorced & 23 & 5.6 \\
\hline & Widow & 12 & 2.9 \\
\hline \multirow[t]{4}{*}{ Level of education } & No formal education & 92 & 22.5 \\
\hline & Primary education & 165 & 40.3 \\
\hline & Secondary education & 98 & 24.0 \\
\hline & College and above & 54 & 13.2 \\
\hline \multirow[t]{4}{*}{ Occupational status } & Employed & 69 & 16.9 \\
\hline & Farmer & 114 & 27.9 \\
\hline & Merchant & 89 & 21.8 \\
\hline & Unemployed & 137 & 33.5 \\
\hline \multirow[t]{2}{*}{ Place of residence } & Rural & 217 & 53.1 \\
\hline & Urban & 192 & 46.9 \\
\hline \multirow[t]{2}{*}{ Average monthly income } & $<1539$ ETB (<56.13 USD) & 320 & 78.2 \\
\hline & $>=1539 \mathrm{ETB}(>=56.13$ USD $)$ & 89 & 21.8 \\
\hline
\end{tabular}

Table 2 Description of clinical and alcohol-related characteristics of tuberculosis patients attending the tuberculosis unit of public health institutions, Gede'o zone, South Ethiopia, $2018(n=409)$

\begin{tabular}{lll}
\hline Variables & Categories & Number (\%) \\
\hline Classification of TB & Pulmonary & $302(73.8)$ \\
& Extra-pulmonary & $107(26.2)$ \\
Phase of treatment & Intensive phase & $250(61.1)$ \\
& Continuation phase & $159(38.9)$ \\
Treatment status & New case & $347(84.8)$ \\
& Re-treatment case & $62(15.2)$ \\
Comorbidity & TB/HIV comorbidity & $71(17.4)$ \\
& Other comorbid condition & $22(5.4)$ \\
Family history of mental & No comorbidity & $316(77.2)$ \\
Illness & No & $23(5.6)$ \\
Duration of illness & $<6$ months & $386(94.4)$ \\
& $6-12$ months & $78(19.1)$ \\
& $>=12$ months & $236(57.7)$ \\
Hazardous alcohol use & No & $95(23.2)$ \\
& Yes & $327(80)$ \\
\hline
\end{tabular}

Psychosocial characteristics of the respondents

Among the total 409 participants, 139 (34\%) had poor social support and 177 (43.3\%) had intermediate social support. Regarding perceived TB stigma, more than onethird of the participants $(38.9 \%)$ had perceived TB stigma (Fig. 1).

\section{Prevalence of depressive symptoms}

The prevalence of depressive symptoms was 45.5\% (95\% $\mathrm{CI}=41.1-50.1)$; $33.3 \%$ had moderate, $9.8 \%$ had moderately severe, and $2.4 \%$ had severe depressive symptoms (Fig. 2).

\section{Factors associated with depressive symptoms among TB patients \\ Bivariate analysis}

In this study, age, marital status, having perceived TB stigma, poor social support, phase of treatment, hazardous alcohol use, medical comorbidity, duration of illness and treatment status were significantly associated with depressive symptoms among TB patients in bivariate analysis (Table 3). 


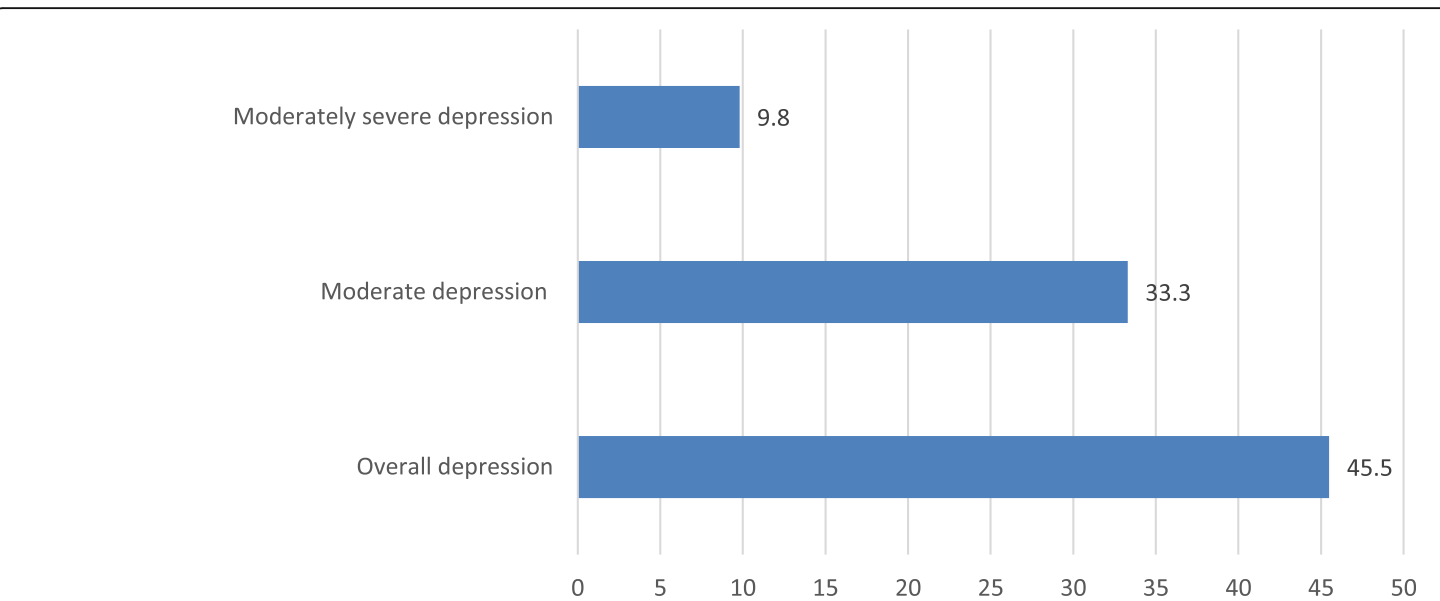

Fig. 1 Percentage distribution of perceived social support of tuberculosis patients attending tuberculosis unit of public health institutions, Gede'o zone, South Ethiopia, $2018(n=409)$

\section{Multivariable analysis}

In the final and fully adjusted multivariable model, TB/ HIV co-infection, being on re-treatment for TB, poor social support, patients aged 45 and above were found to be significantly associated with depressive symptoms among TB patients.

The odds of having depressive symptoms for those patients with TB/HIV coinfection was 3.96 fold higher than those patients who had no TB/HIV coinfection (AOR $=3.96,95 \%$ CI 2.0, 7.84). Regarding social support, those who had poor social support were more than 4 times more likely to develop depressive symptoms than those who have intermediate and strong social support $(\mathrm{AOR}=4.21,95 \% \mathrm{CI}: 2.10-8.47)$.

The study also found that the odds of developing depressive symptoms among those who were on retreatment for TB were 2.47 times higher as compared to those who were on the new $\mathrm{TB}$ treatment category (AOR $=2.47,95 \%$ CI: $1.17-5.22$ ). Those patients aged 45 and above were at 2.41 times higher odds of developing depressive symtoms when compared with those aged 18-24 years $(\mathrm{AOR}=2.41,95 \% \mathrm{CI}: 1.09-5.32)$ (Table 3$)$.

\section{Discussion}

In this study, we found that $45.5 \%$ of patients with TB had depressive symptoms, which is consistent with the reported prevalence from previously published studies from Ethiopia $(43.4 \%$ in Wolaita zone [13], and $49 \%$ Silte and Gurage zone among New TB cases [15]), Nigeria (45.5\%), Pakistan (49.4\%) and China (48.0\%) [13, 14, 29-32].

However, the study prevalence estimates are lower than those reported by prior studies from Cameroon, South Africa, Pakistan, Kashmir, and India, which ranges from 51.9 to $84 \%[15,33-40]$. The differences in the prevalence of depression across the studies could be attributable to several factors, including differences in the sample size, the population being studied, screening tools used, different cut-off scores employed, the study period, classification of tuberculosis and treatment status of TB patients who were in follow up.

Contrarily, the finding of this study was higher compared to the results from studies conducted in Nigeria (27.7\%) [41], Philippines (16.8\%) [22], and India (23.6\%) [42]. The possible explanation for the observed differences could be the difference in population characteristics, the time of assessment (including severity, phases of $\mathrm{Tb}$ treatment and being on $\mathrm{TB}$ medicine or not), as well as the difference in the instruments used to measure depression.

Concerning associated factors, in this study, social support was significantly associated with depressive symptoms among TB patients. Those who had poor social support were more than 4 times more likely to develop depressive symptoms than those who have intermediate and strong social support. The finding was supported by previous epidemiological studies conducted in Ethiopia and India [13,32]. The possible explanation to account for this finding lies in the notion that psychological support is a highly important protective factor against depression in adults with chronic illness. Social support, such as having someone to confide in, attempts to directly reduce the negative feelings associated with a distressing situation [43]. Thus, perceived poor social support diminishes feelings of closeness and being cared for by the family members, and hence compromises individuals' ability to seek help and advice from families and neighbors. On the other hand, having good social support allows the individual to look at the positive aspects of life, thereby resisting the development of negative emotions such as depression [44]. 


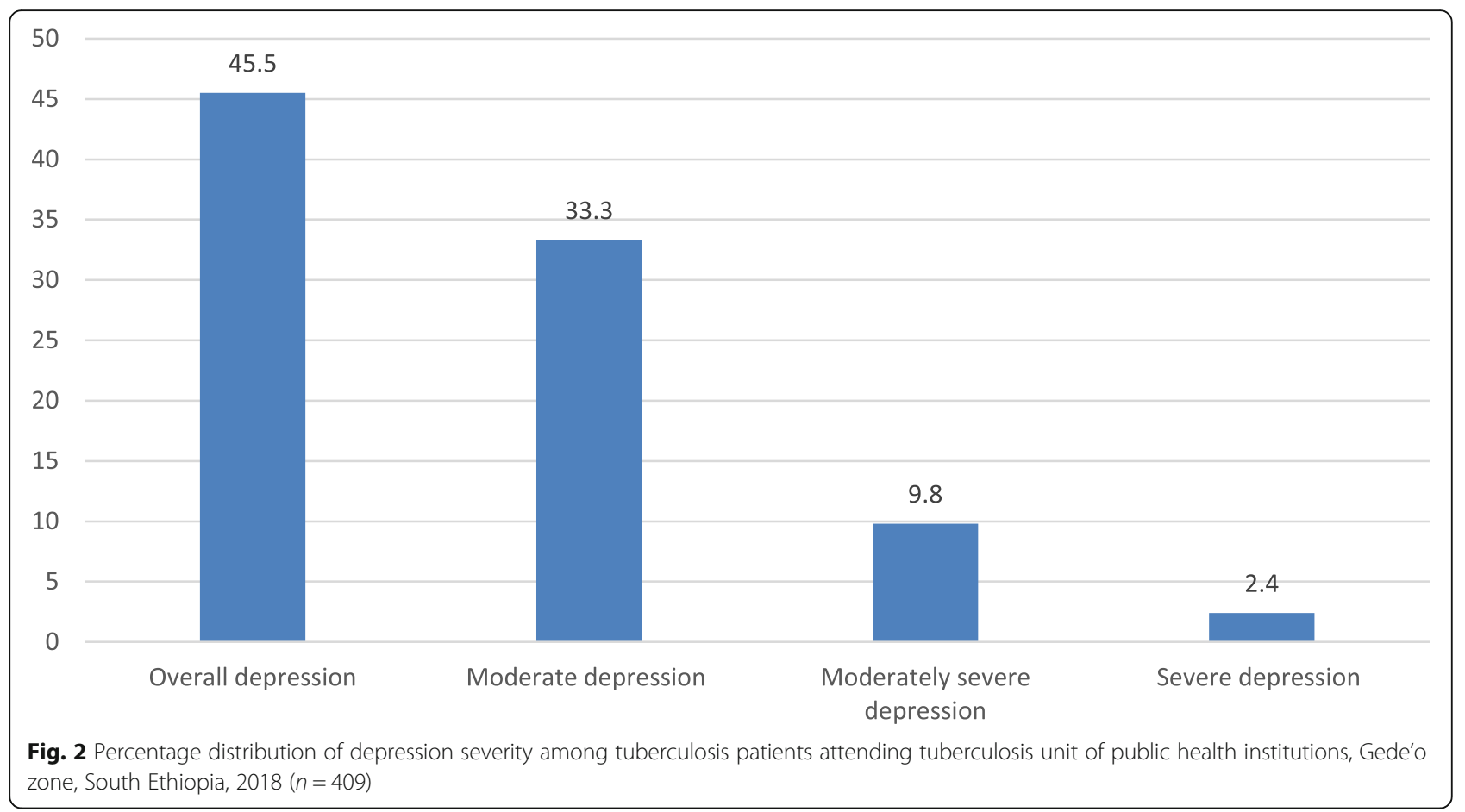

Regarding the comorbid illness, the odds of having depression for those patients with TB/HIV coinfection was 3.96-fold higher than those patients who had no TB/HIV coinfection. This finding was consistent with previous studies $[13,14,34]$. The dual burden of TB/ HIV coinfection among TB patients escalates the probability of poor mental health. In addition to this, the depressive symptoms might be due to the combined side effects of some anti-TB and antiretroviral drugs on the mental health of the patients. Some anti-HIV drugs can affect mental health. Most notably, the non-nucleoside reverse transcriptase inhibitor (NNRTI) efavirenz (Sustiva, also in the combination pill, Atripla) has been associated with depressive symptoms [41, 45].

Treatment status was the other factor that was found to be significantly associated with depressive symptoms among TB patients. The odds of developing depressive symptoms among those who were on re-treatment for TB were 2.47 times higher as compared to those who were on the new TB treatment category. This is consistent with the results reported from studies conducted in Cameroon [34]. The possible explanation to account for this finding lies in the notion that having a previous history of treatment failure, default and relapse to be more prone to worsening of physical condition as well as poor mental health or the depression may predispose patients to do not adhere to their TB medication, which may lead to failure, relapse or default [34].
Finally, those patients aged 45 and above were at 2.41 times higher odds of developing depressive symptoms when compared with those aged 18-24 years. This finding is consistent with findings from previous studies [14, $21,29]$. Although it is difficult to determine causality, it is common to find people who were aged 40 and above to be more prone to depressive symptoms, possibly due to poor social support, family responsibility, loss of a spouse or compromised immunity due to the comorbid illness $[21,29]$.

\section{The strength and limitation of the study}

The study has several strengths. First, the study included important variables that were not included in previous studies. Second, we used the standardized instrument for measuring depression (patient Health Questionnaire9 (PHQ-9). Third, we used a validated and standardized tool for the assessment of independent variables such as alcohol use by Alcohol Use Disorder Identification Test (AUDIT), and TB stigma scale.

A limitation of the study is that the probability of overestimation of the prevalence of depressive symptoms due to the fact that the PHQ-9 has some biological symptoms of TB. Another limitation is due to the design. Since the cross-sectional study design could not show clear risks of depression in TB patients, it was difficult to imply the temporal relationship between significantly associated factors and depression. Additionally, due to the nature of the study design, the researchers cannot distinguish 
Table 3 Bivariate and multivariable analysis of factors associated with depressive symptoms among tuberculosis patients attending tuberculosis unit of public health institutions, Gede'o zone, South Ethiopia, $2018(n=409)$

\begin{tabular}{|c|c|c|c|c|c|}
\hline \multirow[t]{2}{*}{ VARIABLES } & \multirow[t]{2}{*}{ CATEGORIES } & \multicolumn{2}{|c|}{ DEPRESSION } & \multirow[t]{2}{*}{ COR $(95 \% \mathrm{Cl})$} & \multirow[t]{2}{*}{ AOR $(95 \% \mathrm{Cl})$} \\
\hline & & Yes & No & & \\
\hline \multirow[t]{3}{*}{ Marital status } & Married & 104 & 113 & 1 & 1 \\
\hline & Single & 56 & 101 & $0.60(0.39,0.91)$ & $0.81(0.47,1.41)$ \\
\hline & Divorced/ separated & 26 & 9 & $3.13(1.40,7.01)$ & $0.85(0.32,2.23)$ \\
\hline \multirow[t]{4}{*}{ Age of participants } & 18-24 years & 39 & 96 & 1 & 1 \\
\hline & 25-34 years & 62 & 60 & $2.54(1.52,4.25)$ & $1.65(0.86,3.17)$ \\
\hline & $35-44$ years & 48 & 37 & $3.19(1.81,5.64)$ & $1.93(0.89,4.16)$ \\
\hline & 45 and above years & 37 & 30 & $3.03(1.65,5.58)$ & $2.41(1.09,5.32) *$ \\
\hline \multirow[t]{2}{*}{ Hazardous alcohol use } & Yes & 55 & 27 & $3.04(1.82,5.08)$ & $1.65(0.91,3.01)$ \\
\hline & No & 131 & 196 & 1 & 1 \\
\hline \multirow[t]{3}{*}{ Comorbidity } & TB/HIV coinfection & 53 & 18 & $4.94(2.76,8.83)$ & $3.96(2.0,7.84) * * *$ \\
\hline & Another comorbidity & 15 & 7 & $3.59(1.42,9.07)$ & $2.92(0.97,8.77)$ \\
\hline & No comorbidity & 118 & 198 & 1 & 1 \\
\hline \multirow[t]{3}{*}{ Duration of illness } & $<6$ months & 23 & 55 & 1 & 1 \\
\hline & 6-12 months & 111 & 125 & $2.12(1.22,3.68)$ & $1.72(0.90,3.31)$ \\
\hline & $>=12$ months & 52 & 43 & $2.89(1.53,5.58)$ & $0.92(0.40,2.14)$ \\
\hline \multirow[t]{3}{*}{ Perceived social support } & Poor support & 99 & 40 & $7.53(4.14,13.68)$ & $4.21(2.10,8.47) * * *$ \\
\hline & Intermediate support & 64 & 113 & $1.72(0.98,3.02)$ & $1.22(0.63,2.36)$ \\
\hline & Strong support & 23 & 70 & 1 & 1 \\
\hline \multirow[t]{2}{*}{ Treatment status } & New case & 139 & 208 & 1 & 1 \\
\hline & Re-treatment case & 47 & 15 & $4.68(2.52,8.71)$ & $2.47(1.17,5.22) *$ \\
\hline \multirow[t]{2}{*}{ Perceived TB stigma } & Yes & 78 & 81 & $1.26(0.84,1.88)$ & $1.34(0.81,2.21)$ \\
\hline & No & 108 & 142 & 1 & 1 \\
\hline \multirow[t]{2}{*}{ Phase of treatment } & Intensive & 98 & 152 & 1 & 1 \\
\hline & Continuation & 88 & 71 & $1.92(1.28,2.87)$ & $1.69(0.98,2.90)$ \\
\hline
\end{tabular}

Note; $A{ }^{*} p$-value less than $0.05 ;{ }^{* *} p$-value less than $0.01 ;{ }^{* * *} p$-value less than $0.0011=$ reference $P$ value of Hosmer and Lemeshow Test $=0.56$

whether the reported prevalence is due to pre-existing or new-onset cases (depressive symptoms).

\section{Conclusion}

In this study, a considerable percentage of patients with TB had depressive symptoms (45.5\%). Having TB/HIV co-infection, being on re-treatment for $\mathrm{TB}$, those having poor social support, and patients aged 45 and above were found to be significantly associated with depressive symptoms. Therefore, routine screening of depressive symptoms among patients with TB is recommended. Attention needs to be paid for patients having TB/HIV coinfection, being on re-treatment for $\mathrm{TB}$, those having poor social support, and patients aged 45 and above. Moreover, TB patients falling into the risk categories should be more carefully monitored for depressive symptoms and when possible referred to mental health professionals.

\section{Abbreviations}

AUDIT: Alcohol use disorders identification test: PHQ-9: Nine-item patient health questionnaire; MDR-TB: Multiple drug resistance-tuberculosis; NNRTI: Non-nucleoside reverse transcriptase inhibitor; SD: Standard deviation; TB: Tuberculosis; YLD: Years lived with disability

\section{Acknowledgements}

The researchers acknowledge the entire staff of the Gede'o zone Health department, Yirgacheffe, Dilla Zuriya and Wonago district Health facilities for their cooperation in the successful completion of this research. The researcher's sincere gratitude goes to Dilla University, Research and Dissemination Office for funding the study. The researchers also appreciate the study participants for their cooperation in providing the necessary information

\section{Authors' contributions}

KY conceived the research idea. She framed the methods, did the analysis, and wrote the final paper. HM and GA participated in framing the method and write-up. LA, GT, MF and AT involved in write-up. All the authors read and agreed on the final manuscript. The author (s) read and approved the final manuscript.

Funding

This research work was funded by Dilla University. 


\section{Availability of data and materials}

The datasets used and analyzed during the current study are available from the corresponding author on reasonable request.

\section{Ethics approval and consent to participate}

Ethical clearance was obtained from IRB of Dilla University, College of Medicine and Health Sciences. Necessary permission was obtained from the respective localities of Yirgacheffe, Wonago and Dilla Zuriya city administration, health office, and the health centers.

After all permission requests were granted, a permission letter, that explains the purpose of the study and rights of participants, was explained for each participant. Participants were assured that they could withdraw from the study at any time during the study period. Written consent was sought in all cases. The privacy of study participants was fully respected during data collection and dissemination of the findings. Patients with depression and hazardous drinking were referred to a mental health professional for further evaluation and support.

\section{Consent for publication}

Not applicable.

\section{Competing interests}

The authors declare that they have no competing interests.

\section{Author details}

'Department of Psychiatry, College of Medicine and Health Sciences, Dilla University, P.O. Box 419, Dilla, Ethiopia. ${ }^{2}$ School of Public Health, College of Medicine and Health Sciences, Dilla University, Dilla, Ethiopia. ${ }^{3}$ Department of Psychiatry, College of Medicine and Health Sciences, University of Gondar, Gondar, Ethiopia. ${ }^{4}$ Research and Training Department, Amanuel Mental Specialized Hospital, Addis Ababa, Ethiopia. ${ }^{5}$ School of Public Health, Curtin University, Bentley, Perth, Western Australia.

Received: 16 September 2019 Accepted: 29 October 2020

Published online: 13 November 2020

\section{References}

1. Kaplan BJ. Kaplan and sadock's synopsis of psychiatry. Behavioral sciences/ clinical psychiatry. Tijdschr Psychiatr. 2016;58(1):78-9.

2. Depression W. Other common mental disorders: Global Health estimates. Geneva: World Health Organization; 2017. p. 1-24.

3. Nussbaum AM. The pocket guide to the DSM- $5^{\oplus}$ diagnostic exam. American Psychiatric Pub; 2013.

4. Cuijpers P, Beekman AT, Reynolds CF. Preventing depression: a global priority. Jama. 2012;307(10):1033-4.

5. Ferrari AJ, Charlson FJ, Norman RE, Patten SB, Freedman G, Murray CJL, Vos T, Whiteford HA. Burden of depressive disorders by country, sex, age, and year: findings from the global burden of disease study 2010. PLoS Med. 2013;10(11):e1001547.

6. Hailemariam S, Tessema F, Asefa M, Tadesse H, Tenkolu G. The prevalence of depression and associated factors in Ethiopia: findings from the National Health Survey. Int J Ment Heal Syst. 2012;6(1):23.

7. Pachi A, Bratis D, Moussas G, Tselebis A. Psychiatric morbidity and other factors affecting treatment adherence in pulmonary tuberculosis patients. Tuberc Res Treat. 2013;2013.

8. Duarte EC, Bierrenbach AL, da Silva JB, Tauil PL, de Fátima DE. Factors associated with deaths among pulmonary tuberculosis patients: a casecontrol study with secondary data. J Epidemiol Community Health. 2009; 63(3):233-8.

9. Kasper DL. HARRISON'S TM Infectious Diseases. Mexico City; 2013.

10. Sweetland A, Kritski A, Oquendo M, Sublette M, Norcini Pala A, Silva L, Karpati A, Silva E, Moraes M, Silva J. Addressing the tuberculosis-depression syndemic to end the tuberculosis epidemic. Int J Tuberc Lung Dis. 2017; 21(8):852-61.

11. Organization WH. Global tuberculosis report 2018: World Health Organization; 2018.

12. Organization WH. Global tuberculosis report 2013: World Health Organization; 2013.

13. Duko B, Gebeyehu A, Ayano G. Prevalence and correlates of depression and anxiety among patients with tuberculosis at WolaitaSodo University hospital and Sodo health center, WolaitaSodo, South Ethiopia, cross sectional study. BMC Psychiatry. 2015;15(1):214.

14. Adem A, Markos T, Mohammed A. The prevalence and pattern of depressıon in patıents with tuberculosis on follow-up at Jimma university specialized hospital and Jimma health center. Med Sci. 2013;3(1):955-68.

15. Ambaw F, Mayston R, Hanlon C, Alem A. Burden and presentation of depression among newly diagnosed individuals with TB in primary care settings in Ethiopia. BMC Psychiatry. 2017;17(1):57.

16. Louw J, Peltzer K, Naidoo P, Matseke G, Mchunu G, Tutshana B. Quality of life among tuberculosis (TB), TB retreatment and/or TB-HIV co-infected primary public health care patients in three districts in South Africa. Health Qual Life Outcomes. 2012;10(1):77.

17. Kastien-Hilka T, Abulfathi A, Rosenkranz B, Bennett B, Schwenkglenks M, Sinanovic E. Health-related quality of life and its association with medication adherence in active pulmonary tuberculosis-a systematic review of global literature with focus on South Africa. Health Qual Life Outcomes. 2016;14(1):42.

18. Ugarte-Gil C, Ruiz P, Zamudio C, Canaza L, Otero L, Kruger H, Seas C. Association of major depressive episode with negative outcomes of tuberculosis treatment. PLoS One. 2013;8(7):e69514.

19. Theron G, Peter J, Zijenah L, Chanda D, Mangu C, Clowes P, Rachow A, Lesosky M, Hoelscher M, Pym A. Psychological distress and its relationship with non-adherence to TB treatment: a multicentre study. BMC Infect Dis. 2015;15(1):253.

20. Sulehri MA, Dogar IA, Sohail H, Mehdi Z, Azam M, Niaz O, Javed MS, Sajjad IA, lqbal Z: Prevalence of depression among tuberculosis patients. In: APMC: 2010; 2010: 133-137.

21. Peltzer K, Naidoo P, Matseke G, Louw J, Mchunu G, Tutshana B. Prevalence of psychological distress and associated factors in tuberculosis patients in public primary care clinics in South Africa. BMC Psychiatry. 2012;12(1):89.

22. Masumoto S, Yamamoto T, Ohkado A, Yoshimatsu S, Querri AG, Kamiya Y. Prevalence and associated factors of depressive state among pulmonary tuberculosis patients in Manila, the Philippines. Int J Tuberc Lung Dis. 2014; 18(2):174-9

23. Naidoo P, Mwaba K. Helplessness, depression, and social support among people being treated for tuberculosis in South Africa. Soc Behav Personal Int J. 2010:38(10):1323-33.

24. Abiola T, Udofia O, Zakari M. Psychometric properties of the 3-item Oslo social support scale among clinical students of Bayero University Kano, Nigeria. Malays J Psychiatry. 2013;22(2):32-41.

25. Redwood L, Daftary A, Lewis D, Mitchell EM. Measuring TB stigma among people with TB using scales. TB Stigma. 2018:132.

26. Van Rie A, Sengupta S, Pungrassami P, Balthip Q, Choonuan S, Kasetjaroen Y, Strauss RP, Chongsuvivatwong V. Measuring stigma associated with tuberculosis and HIV/AIDS in southern Thailand: exploratory and confirmatory factor analyses of two new scales. Tropical Med Int Health. 2008;13(1):21-30.

27. Chishinga N, Kinyanda E, Weiss HA, Patel V, Ayles H, Seedat S. Validation of brief screening tools for depressive and alcohol use disorders among TB and HIV patients in primary care in Zambia. BMC Psychiatry. 2011;11(1):75.

28. Gelaye B, Williams MA, Lemma S, Deyessa N, Bahretibeb Y, Shibre T, Wondimagegn D, Lemenhe A, Fann JR, Vander Stoep A. Validity of the patient health questionnaire-9 for depression screening and diagnosis in East Africa. Psychiatry Res. 2013;210(2):653-61.

29. Ige OM, Lasebikan VO. Prevalence of depression in tuberculosis patients in comparison with non-tuberculosis family contacts visiting the DOTS clinic in a Nigerian tertiary care hospital and its correlation with disease pattern. Ment Health Fam Med. 2011;8(4):235.

30. Ahmed MM. Depression in tuberculosis patients and its relationship to socio demographic factors. J Rawalpindi Med Coll. 2016;20(4):296-9.

31. Gong Y, Yan S, Qiu L, Zhang S, Lu Z, Tong Y, Fang P, Yin X. Prevalence of depressive symptoms and related risk factors among patients with tuberculosis in China: a multistage cross-sectional study. Am J Trop Med Hyg. 2018;98(6):1624-8.

32. Dahiya S, Khichi SK, Goel PK, Singh A, Singh NK. Prevalence of depression among tuberculosis patients. Sch J App Med Sci. 2017:5:2212-5.

33. Dasa T, Roba AA, Weldegebreal F, Mesfin F, Asfaw A, Mitiku H, Teklemariam Z, Geddugol BJ, Naganuri M, Befikadu H. Prevalence and associated factors of depression among tuberculosis patients in eastern Ethiopia. BMC Psychiatry. 2019;19(1):82. 
34. Kehbila J, Ekabe CJ, Aminde LN, Noubiap JJN, Fon PN, Monekosso GL. Prevalence and correlates of depressive symptoms in adult patients with pulmonary tuberculosis in the southwest region of Cameroon. Infect Dis Poverty. 2016;5(1):51

35. Amreen NR. Frequency of depression and anxiety among tuberculosis patients. J Tuberc Res. 2016:4:183-90.

36. Basu G, Chatterjee C, Singh R, Biswas S. Prevalence of depression in tuberculosis patients: an experience from a DOTS clinic. IJRRMS. 2012;2(4): 14-7.

37. Mandaknalli R, Giriraj B. Prevalence of depression in tuberculosis patients in a tertiary hospital care hospital. Sch J App Med Sci. 2015;3:2445-8.

38. Bhat SA, Shah SA. Study of Depression, anxiety and stress among tuberculosis patients and its relation with their life satisfaction. J Med Sc Clin Res. 2015;3(6):6107-15.

39. Tariq A, Arshad S, Ejaz M. Frequency of Depression in tuberculosis patients and its association with various Sociodemographic factors. Pak J Med Health Sci. 2018;12(1):42-5.

40. Gul E, Ali S, Jalal M, Haq MU. Frequency of Depression in patients suffering from pulmonary tuberculosis. Pak J Chest Med. 2017;23(1):03-7.

41. Kenedi CA, Goforth HW. A systematic review of the psychiatric side-effects of efavirenz. AIDS Behav. 2011;15(8):1803-18.

42. Salodia UP, Sethi S, Khokhar A. Depression among tuberculosis patients attending a DOTS Centre in a rural area of Delhi: a cross-sectional study. Indian J Public Health. 2019:63(1):39.

43. Gariepy G, Honkaniemi H, Quesnel-Vallee A. Social support and protection from depression: systematic review of current findings in Western countries. Br J Psychiatry. 2016;209(4):284-93.

44. Wang X, Cai L, Qian J, Peng J. Social support moderates stress effects on depression. Int J Ment Heal Syst. 2014;8(1):41

45. Leutscher PDC, Stecher C, Storgaard M, Larsen CS. Discontinuation of efavirenz therapy in HIV patients due to neuropsychiatric adverse effects. Scand J Infect Dis. 2013;45(8):645-51.

\section{Publisher's Note}

Springer Nature remains neutral with regard to jurisdictional claims in published maps and institutional affiliations.

Ready to submit your research? Choose BMC and benefit from:

- fast, convenient online submission

- thorough peer review by experienced researchers in your field

- rapid publication on acceptance

- support for research data, including large and complex data types

- gold Open Access which fosters wider collaboration and increased citations

- maximum visibility for your research: over $100 \mathrm{M}$ website views per year

At $\mathrm{BMC}$, research is always in progress.

Learn more biomedcentral.com/submissions 